\title{
Outcome of isolated congenital complete heart block diagnosed in utero
}

\author{
Alison M M Groves, Lindsay D Allan, Eric Rosenthal
}

\begin{abstract}
Objective-To establish identifiable prenatal factors in fetal heart block which might predict death in utero, the need for intervention, or the probability of pacemaker requirement.
\end{abstract}

Setting-Tertiary referral unit for fetal echocardiography.

Subjects-36 fetuses with congenital complete heart block and structurally normal hearts identified between 1980 and 1993. Methods-Maternal anti-Ro antibody status was documented. Prenatal variables examined included absolute heart (ventricular) rate, change in rate, and development of hydrops fetalis. Postnatally, heart rate, need for pacing, and the indications for pacing were detailed.

Results-Of the total of 36 patients, there are 24 survivors; 11 are paced. Of those fetuses which died, two were electively aborted for severe hydrops, seven died in utero, two were immediate postnatal deaths, and one was an unrelated infant death. The trend was for the heart rate to decrease during fetal life and postnatally. Fetuses with deteriorating cardiac function did not always show the lowest heart rates. Bradycardia of less than 55 beats/min in early pregnancy or rapid decrease in heart rate prenatally were poor prognostic signs. Hydrops was also associated with bad outcome, 10 out of the 12 hydropic fetuses dying (83\%). Of 10 fetuses presenting with a heart rate above $60 / \mathrm{min}$, nine survived of whom three required pacing. Of seven presenting with heart rates of $50 / \mathrm{min}$ or less, only three survived and two of these required pacing. Of the two fetuses with negative maternal anti-Ro antibody status one died in utero and one required heart transplantation after pacemaker insertion.

Conclusions-Isolated complete heart block identified in fetal life does not always have a good prognosis. An individual heart rate does not accurately predict the outcome in utero or the need for postnatal pacing. Regular, careful monitoring during pregnancy is required in order to optimise care and timing of any interventions.

(Heart 1996;75:190-194)

Keywords: fetal heart block; pacing; hydrops fetalis; cardiac function
Morquio, in 1901, was first to describe "complete heart block" in several members of one family. ${ }^{1}$ The first electrocardiographic analysis was reported in $1908 .^{2}$ Identification in the fetus came in 1945, when the diagnosis was made by auscultation and electrocardiography. ${ }^{3}$ Electrocardiography is technically difficult and echocardiography has become the method of choice for the detection and analysis of fetal arrhythmias. ${ }^{4-6}$

An association between fetal isolated complete heart block and maternal connective tissue disease has been described. ${ }^{78}$ Pathological changes have been directly related to circulating maternal anti-Ro antibodies, even in the absence of clinical disease. ${ }^{9}$ Histologically there is fibrous replacement of the conducting tissue. ${ }^{1011}$

In 1988 we reported our clinical experience of complete heart block in the fetus: 16 cases with isolated complete heart block and 21 of heart block with structural heart disease (17 with left atrial isomerism). Fetal outcome with isolated heart block was good, compared with a mortality of $85 \%$ in those with structural heart disease. ${ }^{12}$ It has since become evident that cardiac failure and death can occur in isolated heart block. ${ }^{13-15}$ This natural history has led to interventions including premature delivery, ${ }^{16}$ administration of inotropes, ${ }^{17}$ steroids and/or plasmapheresis ${ }^{18}$ and transabdominal pacing of the fetus. ${ }^{19}$

Since 1980, we have diagnosed isolated complete heart block in 36 fetuses, including one set of twins. An analysis of the outcome of the group-the largest single centre series to date - was undertaken in order to establish any risk factors identifiable prenatally which might predict in utero death or pacemaker requirement. These would be relevant for prenatal intervention, site of delivery, timing and management of labour, and parental counselling.

\section{Methods}

Between 1980 and January 1994, 36 fetuses with isolated congenital complete heart block were identified from 10600 referrals for fetal echocardiography. The reason for referral was detection of a fetal bradycardia in 34 patients and presence of maternal antibodies in threeone with a previous child with isolated heart block. Antibody status was established in 33 patients using enzyme linked immunosorbant assay (ELISA). One patient was on high dose steroids for systemic lupus erythematosus before conception.

The diagnosis was established on cross 
Table 1 Outcome of 36 fetuses (one set twins)

\begin{tabular}{ll}
\hline Antibody status-34 tested & $32(94 \%)$ \\
Ro positive & $7(20 \%)$ \\
$\begin{array}{l}\text { Clinically apparent connective } \\
\quad \text { tissue disease }\end{array}$ & $3(8 \cdot 5 \%)$ \\
$\begin{array}{l}\text { Previous sibling with documented } \\
\text { CHB }\end{array}$ & \\
Presence of hydrops & 7 \\
Early & 5 \\
Late & 4 \\
Pericardial effusion only & \\
Outcome & 2 \\
Termination of pregnancy (TOP) & 7 \\
Intrauterine death (IUD) & 2 (1 temporarily paced) \\
Neonatal death (NND) & 1 (non-cardiac) \\
Infant death (INFD) & 13 \\
Alive and well, not paced & 11 (1 transplant, 1 alive \\
Alive, paced & with neurological \\
& problems) \\
\hline
\end{tabular}

sectional imaging using an Advanced Technical Laboratories mark 4 or a Hewlett Packard 77020A ultrasound scanner. At each visit heart rate was calculated by the average of three $M$ mode or Doppler readings, preferably at rest, and cardiac function evaluated using $M$ mode shortening fraction and arterial Doppler peak velocities. Evidence of intrauterine cardiac failure - skin oedema, ascites, and pericardial or pleural effusion-was recorded. With increasing experience patients were

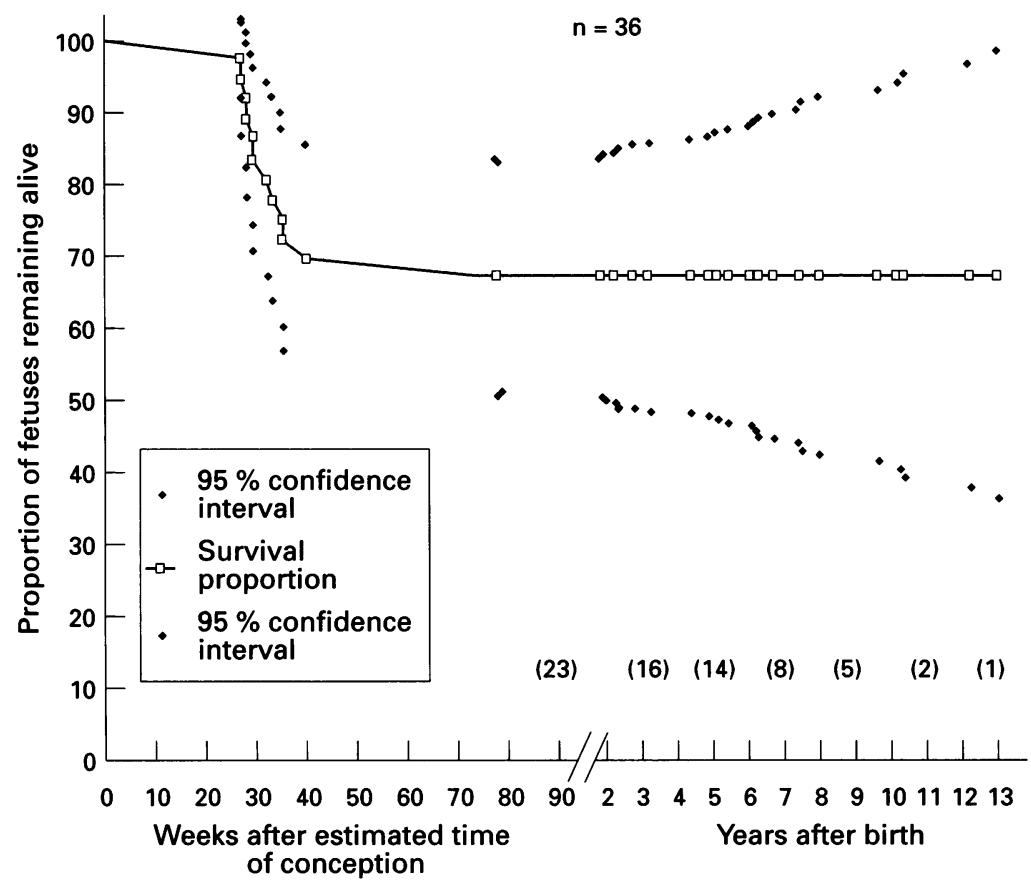

Figure 1 Kaplan-Meyer survival curve for congenital complete heart block detected prenatally. This curve shows that the major attrition of patients in the prenatal series is antenatal. The non-cardiac death has been excluded. There was no fetal loss before 27 weeks gestation. Numbers in parenthesis are the numbers of patients alive at the follow up interval.

Table 2 Indications for pacing

\begin{tabular}{|c|c|c|c|c|c|c|}
\hline & \multirow{2}{*}{\multicolumn{4}{|c|}{ Symptomatic }} & \multicolumn{2}{|l|}{ Asymptomatic } \\
\hline & & & & & \multirow{2}{*}{$\begin{array}{l}\text { Bradycardia } \\
+ \text { long } Q T \\
\text { + pauses }\end{array}$} & \multirow[b]{2}{*}{$\begin{array}{l}\text { Bradycardio } \\
+ \text { exit block }\end{array}$} \\
\hline & $C C F$ & Syncope & $F T T$ & $\begin{array}{l}\text { Exercise } \\
\text { intolerance }\end{array}$ & & \\
\hline $\begin{array}{l}\text { No of } \\
\text { cases }\end{array}$ & 2 & 2 & 1 & 1 & 3 & 2 \\
\hline $\begin{array}{l}\text { Age at } \\
\text { pacing }\end{array}$ & $4 d, 14 d$ & $9 \mathrm{~m}, 9 \mathrm{~m}$ & $4 \mathrm{~m}$ & $8 y$ & $8 d, 12 d, 4 m$ & $4 y, 6 y$ \\
\hline
\end{tabular}

$\mathrm{CCF}$, congestive cardiac failure; FTT, failure to thrive. reviewed more frequently, four to six weekly initially, but two weekly if any signs of cardiac failure were noted.

Postnatal electrocardiography confirmed the diagnosis in all live deliveries. The heart rates were recorded by clinical observation or by 12 -lead electrocardiogram and by ambulatory electrocardiographic analysis. The age and criteria used for pacing were recorded. Details in all surviving patients were obtained from the relevant paediatric cardiology centre.

Necropsy analysis of the cardiac structure and the histology of the conducting tissue were sought where possible.

The results were assessed for significance using the $\chi^{2}$ test and significance was assumed at $\mathrm{P}<0.05$.

\section{Results}

PRENATAL COURSE

The findings in the total group of 36 cases of prenatal isolated complete heart block are summarised in table 1 . Of nine in utero deaths, only one fetus was not hydropic and had no signs of deteriorating cardiac function. Necropsy examination did not reveal any abnormalities other than fibrosis of the bundle. One of the in utero fetal deaths had negative maternal anti-Ro antibody. Histology showed interruption of the bundle of $\mathrm{His}$ in contrast to the fibrosis of those with antibody.

\section{HYDROPIC FETUSES}

Twelve patients developed significant intrauterine hydrops. Two of these survived-one showed spontaneous resolution and the other had a course of sympathomimetic treatment which appeared to reverse the deterioration in ventricular function, with resolution of hydrops. Neither has required pacing postnatally. Three mothers were given steroids without any improvement in the fetus. Two pregnancies were electively interrupted in view of the severity of fetal hydrops. Two of the hydropic infants were delivered prematurely. One died of cardiac and renal failure before pacing was instigated. The other died, despite

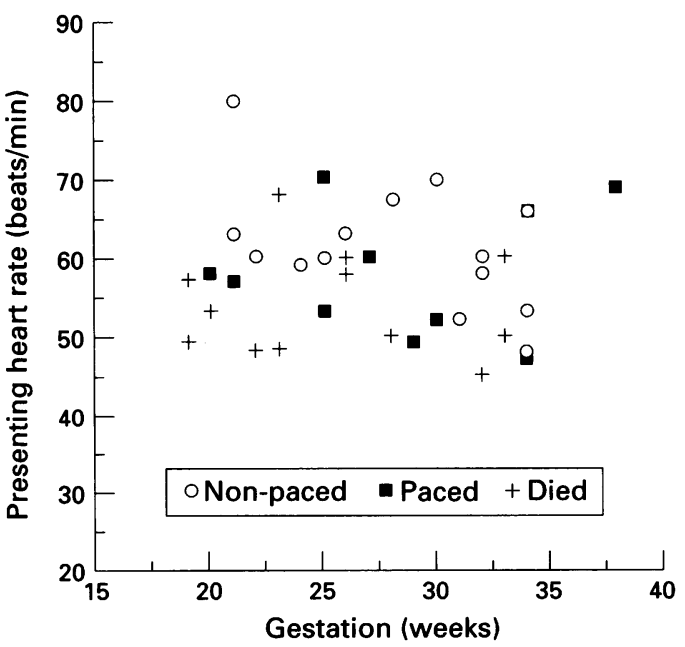

Figure 2 The relation of presenting heart rate to outcome. There is a wide scatter overall with some clustering of the patients with poor outcome at lower rates. 
Figure 3 Prenatal heart rates of fetuses scanned more than once, grouped according to outcome. Each set of symbols joined by $a$ line represents a patient.
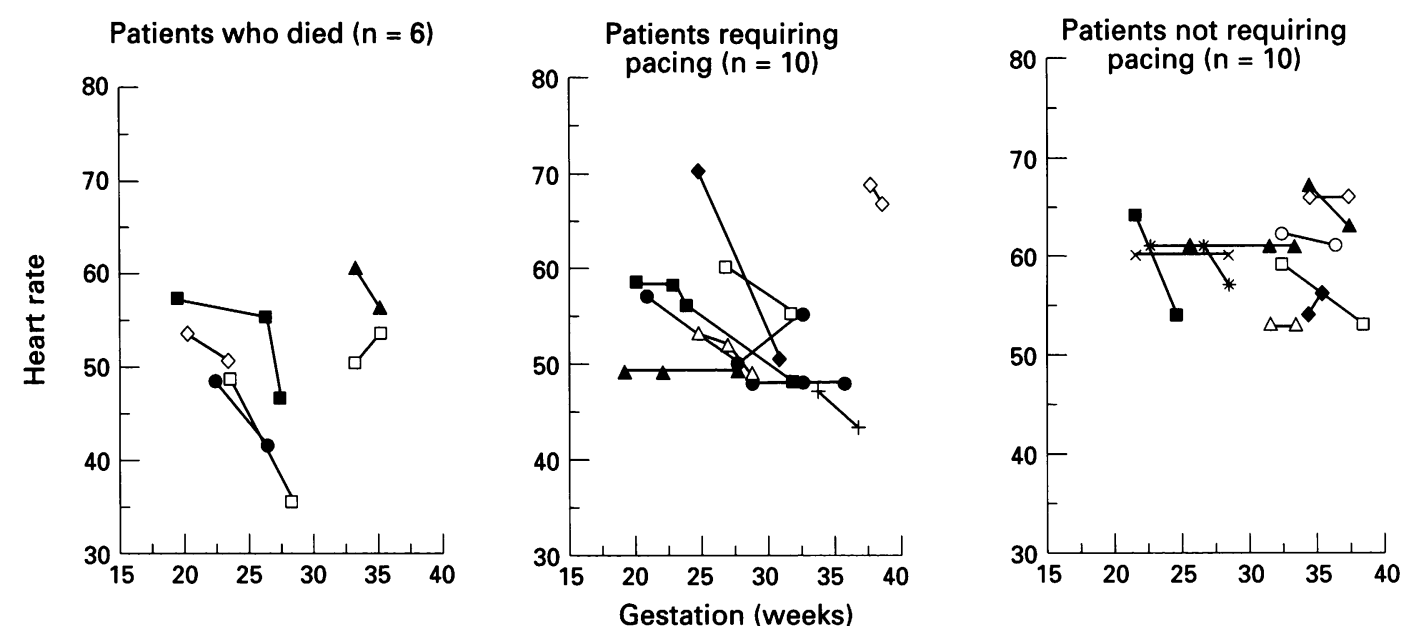

Figure 4 Averaged heart rates at presentation, birth, and most recent follow up of patients who died in utero or early neonatal period (excluding the pertussis death), those who survived having been paced, and survivors who have not needed pacing. The differences were not statistically significant. IUD, intrauterine death; NND, early neonatal death.

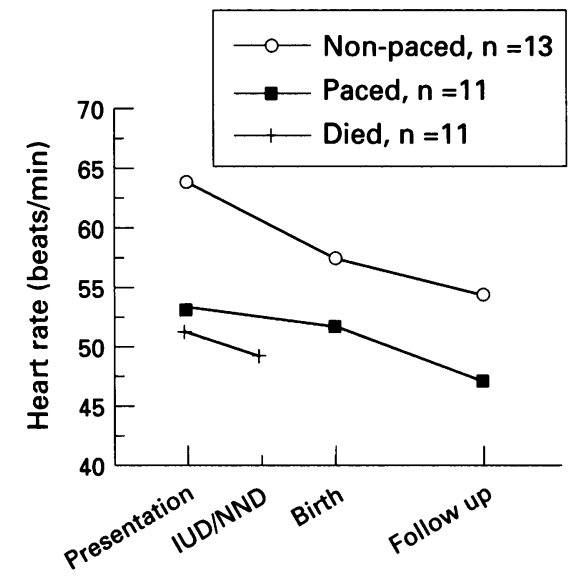

pacing, at 10 days. Four fetuses developed an isolated pericardial effusion without evidence of ventricular dysfunction. These resolved spontaneously postnatally.

\section{POSTNATAL COURSE}

One patient died in infancy of pertussis infection. To date there has been no further mortality (fig 1).

One patient who had a satisfactory heart rate on $24 \mathrm{~h}$ monitoring had a cardiac arrest at 4 months and was paced after resuscitation. She now has a severe neurological handicap. Retrospective analysis showed a prolonged QT interval of $648 \mathrm{~ms}$ and heart rate $60 / \mathrm{min}$ with no ventricular arrhythmia noted.

One of the survivors had negative maternal anti-Ro status. This patient was paced but required cardiac transplantation for cardiomyopathy. The excised heart specimen showed interruption of the bundle of His.

Table 3 Outcome of prenatally diagnosed isolated heart block

\begin{tabular}{llllllll}
\hline $\begin{array}{l}\text { Heart rate at } \\
\text { presentation }\end{array}$ & Total & Hydropic & $\begin{array}{l}\text { Died } \\
\text { (IUD) }\end{array}$ & $\begin{array}{l}\text { Died } \\
\text { (PND) }\end{array}$ & $\begin{array}{l}\text { Paced } \\
<1 \text { yr }\end{array}$ & $\begin{array}{l}\text { Paced } \\
>1\end{array}$ yr & $\begin{array}{l}\text { Not } \\
\text { paced }\end{array}$ \\
\hline$>60$ & 10 & 1 & 1 & & 3 & 0 & 6 \\
$56-60$ & 12 & 4 & 3 & $1 \dagger$ & 3 & 1 & 4 \\
$51-55$ & 7 & 2 & $3^{\star}$ & & 1 & 1 & 2 \\
$<50$ & 7 & 5 & 2 & $2 \ddagger$ & 1 & 1 & 1 \\
\hline
\end{tabular}

^Includes two pregnancies terminated for severe hydrops. IUD, intrauterine death; PND, postnatal death, includes one $(\dagger)$ non-cardiac and two $(\ddagger)$ delivered prematurely.
Of the 24 surviving patients with isolated complete heart block diagnosed in utero, 11 $(46 \%)$ have required pacing so far. Maximum follow up duration is 12 years, minimum six months, mean $5 \frac{1}{2}$ years. Table 2 outlines the age and indication for pacing.

IN UTERO HEART RATE

One patient had a normal heart rate at 18 weeks gestation which evolved into complete heart block by 22 weeks. Otherwise, heart rate at presentation varied between 45 and 80 beats/min, with overall a higher rate earlier in gestation. Fetal heart rate increased with activity (fig 2). Most fetuses showed no significant change in heart rate with advancing gestation, but of 25 who had more than one examination, nine showed a decrease of more than 5 beats $/ \mathrm{min}$. Of these, five died in utero $(P<0.001)$, two showed an increased rate, and one of these fetuses subsequently died (fig 3).

Heart rate at presentation was 51 (SD 6.8) beats/min for those who died, $53(8 \cdot 1)$ beats/min in those who survived but required pacing, and $64(8.3)$ beats/min in those survivors not requiring pacing (fig 4). However, the difference between the heart rate at presentation of infants paced but alive and those who died was not significant, and there was no significant difference between rates at presentation of the paced versus non-paced survivors.

Of 10 fetuses presenting with a heart rate above $60 / \mathrm{min}$, nine survived $(90 \%)$ and only three have required pacing so far $33 \%$ of survivors). Meanwhile, of seven presenting with a rate of 50 or less, only three survived $(42 \%)$ and two of these three have required pacing (table 3). A presenting heart rate less than $55 / \mathrm{min}$ before 28 weeks gestation was associated with death in five and permanent pacemaker in the other one of six fetuses. This reached statistical significance on $\chi^{2}$ analysis $(P<0.001 ;$ fig 2$)$.

\section{Discussion}

Isolated congenital complete heart block in the fetus has been well described. The association with maternal anti-Ro antibody has also been 
widely documented. Intrauterine cardiac failure leading to fetal or neonatal loss has become more widely reported. ${ }^{121415}$ In our current series the greatest attrition occurred prenatally, heart failure affecting 12 of our 36 cases. Perinatal loss occurred in 10 of these cases, which is comparable to hydropic deaths in all four of 26 cases in a combined report from three centres. ${ }^{15}$

We have not shown an absolute relation between the initial ventricular rate and outcome but agree with other investigators that rates below $55 / \mathrm{min}$ during early pregnancy have a worse prognosis. ${ }^{1315}$ However the wide scatter makes it difficult to give a prognosis in any one case (fig 2). Our findings are comparable with the postnatal series without structural cardiac defects reported by Sholler and Walsh. ${ }^{20}$ The majority (56\%) of fetuses maintained the same rate. In $36 \%$ heart rate fell with advancing gestation, and where it decreased by 5 beats/min or more the mortality was $55 \%$. Two patients in the group showed a small increase in heart rate, indicating some variability with activity already documented in children with heart block. $^{21}$ One of these fetuses died in utero, which was perhaps surprising as the ability to increase heart rate with exercise is associated with favourable outcome postnatally. 2223

Successful maternal prophylaxis has been claimed for steroids and plasmapheresis in individual cases. However, as the recurrence risk is only $8-20 \%$, treatment efficacy has not been established. ${ }^{9}$ Prenatal intervention in the hydropic affected fetus has also been tried. Three such patients were given steroids with no success, but we have had success with salbutamol in one patient in our unit. ${ }^{17}$ In one report direct intrauterine pacing was technically successful for some hours before fetal death. ${ }^{19}$ Long term problems would be potential sepsis, displacement of the wire, or fetal limb damage from it. Future devices might be implanted under the fetal skin.

The major attrition in our series is prenatally and immediately postnatally in those delivered prematurely for worsening hydrops. All but one was hydropic. ${ }^{13}$ There has been no mortality related to heart block beyond the neonatal period.

The decreasing heart rate seen in serial prenatal scans often continued into postnatal life, perhaps because of fibrosis extending to the bundle of His. ${ }^{11}$

Endocardial pacing in childhood is now technically reliable although not undertaken without clear indications. Permanent pacing was required in 11 patients, $55 \%$ of whom were symptomatic. Asymptomatic cases did not have absolute indications for pacing, but low heart rates and either long QT or exit block with pauses were the basis of the decision to pace in our unit and other paediatric cardiology centres. The combination of a low heart rate with long QT interval had a significantly poor outcome in a postnatal multicentre series. ${ }^{23}$ The patient who was paced only after cardiac arrest illustrates the importance of assessment of QT interval. ${ }^{25}$
The two cases which showed repeated negative maternal anti-Ro antibody both had poor outcomes. One died prenatally and the other required cardiac transplantation-both hearts showing interruption of the bundle of His of a familial type. This may have represented a new mutation or incomplete family history.

\section{CONCLUSIONS}

Reviewing our series of patients with isolated complete heart block we found a heart rate below 55 beats/min in early pregnancy, or one which drops below 50 beats/min, is associated with greater likelihood of poor outcome. The likelihood of requiring early pacemaker insertion, however, cannot be predicted with certainty from the prenatal heart rate. These patients should therefore be monitored at frequent intervals, every one to two weeks, or monthly for those at lower risk, searching particularly for early evidence of cardiac decompensation. In this way the optimum decision would be made with respect to possible antenatal treatment, early delivery, perinatal monitoring without cardiotocographic assistance, and management of the hydropic neonate.

We would like to acknowledge the assistance of Dr J Till, Roya Brompton and National Heart Hospital, for outcome details.

1 Morquio L. Sur un maladie infantile caracterisée par des modifications permanente du pouls, des attaques syncopales et épileptiformes et la mort subite. Arch Med Enfants 1901;4:467-75

2 Yater WM. Congenital heart block: review of the literature-report of a case with incomplete heterotaxy: the electrocardiogram in dextrocardia. $\mathrm{Am} f \mathrm{Dis}$ Child 1929;38:112-36.

3 Plant RK, Steven RA. Complete atrioventricular block in fetus. Am Heart 7 1945;102:117-22.

4 Crawford D, Chapman M, Allan LD. The assessment of persistent bradycardia in prenatal life. Br $\mathcal{f}$ Obstet Gynaecol 1985;92:941-4.

5 Allan LD, Anderson RH, Sullivan ID, Campbell S, Holt DW, Tynan M. Evaluation of fetal arrhythmias by echocardiography. Br Heart f 1983;50:240-5.

6 Gembruch U, Hansmann M, Redel DA, Bald R, Knopfle G. Fetal complete heart block: antenatal diagnosis, significance and management. Eur $\mathcal{f}$ Obst Gynecol 1989;31:9-22

7 Hull D, Binns BAO, Joyce D. Congenital heart block and widespread fibrosis due to maternal lupus erythematosus. Arch Dis Child 1966;41:688-90.

8 McCue CM, Mantakas ME, Tingelstad JB, Ruddy S. Congenital heart block in newborns of mothers with connective tissue disease. Circulation 1977;56:82-90.

9 Scott JS, Maddison PJ, Taylor PV, Esscher E, Scott O, Skinner RP. Connective tissue disease, antibodies to ribonucleoprotein, and congenital heart block. $N$ Engl $\mathcal{F}$ Med 1985;312:98-100.

10 Lev M, Silverman J, Fitzmaurice FM, Paul MH, Cassels DE, Miller RA. Lack of connection between the atria and the more peripheral conduction system in congenital the more peripheral conduction system in congen

11 Ho SY, Fagg N, Anderson RH, Cook A, Allan LD Disposition of the atrioventricular conduction tissues in Disposition of the atrioventricular conduction tissues in the heart with isomerism of the atrial appendages: its relation to congenital complete heart block. $\mathrm{F} \mathrm{Am}$ Coll Cardiol 1992;20:904-10.

12 Machado MVL, Tynan MJ, Curry PVL, Allan LD. Fetal complete heart block. Br Heart $\mathcal{F}$ 1988;60:512-5.

13 Kleinman CS, Donnerstein RL. Ultrasound assessment of cardiac function in the intact human fetus. $\mathcal{F} \mathrm{Am}$ Coll Cardiol 1985;5:84-94S.

14 Serwer GA, Vermillion RP, Snider AR, Dick M, Crowley DC, Hayashi RH. Prognostic indicators for fetuses with in utero diagnosed complete heart block [abstr]. Circulation 1988;78(suppl II):II-397.

15 Schmidt KG, Ulmer HE, Silverman NH, Kleinman CS, Copel JA. Perinatal outcome of fetal complete atrioventricular block: a multicenter experience. $\mathcal{F} \mathrm{Am}$ Coll Cardiol $1991 ; 17: 1360-6$

16 Martin TC, Arias F, Oglander DS, Hoffman RJ, Marburger JP, Maurer MM. Successful management of congenital atrioventricular block associated with hydrops fetalis. F Pediatr 1988;112:984-6.

17 Groves AMM, Allan LD, Rosenthal E. Therapeutic use of inotropes in complete heart block in the fetus [abstr]. $\mathrm{Br}$ Heart $尹$ 1993;69:17s. 
18 Barclay CS, French MAH, Ross LD, Sokol RJ. Successful pregnancy following steroid therapy and plasma
exchange in a woman with anti-Ro (SS-A) antibodies. Case report. Br $\mathcal{f}$ Obstet Gynaecol 1987;94: bodies.

19 Carpenter RJ, Strasburger JF, Garson A, Smith RT, Deter RL, Engelhardt HT. Fetal ventricular pacing for hydrop secondary to complete atrioventricular block. $\mathcal{F} \mathrm{Am} \mathrm{Coll}$ Cardiol 1986;8:1434-6.

20 Sholler GF, Walsh EP. Congenital complete heart block in patients without anatomic cardiac defects. Am Heart 1989;118:1193-8.

21 Michaelsson M, Engle MA. Congenital complete heart block: an international study of the natural history. Cardiovasc Clin 1972;4:85-101.
22 Dewey RC, Capeless MA, Levy AM. Use of ambulatory electrocardiographic monitoring to identify high-risk patients with congenital complete heart block. $N$ Engl $\mathcal{F}$ Med 1987;14:835-9.

23 Pinskey WM, Gillette PC, Garson A, McNamara DG. Diagnosis, management, and long-term results of patients with congenital complete atrioventricular block. Pediatrics 1982;69:728-33.

24 Karpawich PP, Gillette PC, Garson A, Hesslein PS, Porter C-B, Macnamara DG. Congenital complete atrioventricular block: clinical and electrophysiologic predictors of need for pacemaker insertion. Am $\mathcal{f}$ Cardiol 1981;48: 1098-102.

25 Esscher E, Michaelsson M. Q-T interval in congenital complete heart block. Pediatr Cardiol 1983;4:121-4.

\title{
ABSTRACTS IN CARDIOLOGY
}

\section{Rheumatic fever: pathogenesis revealed}

Generations of medical students have been taught concepts about the pathogenesis of rheumatic fever which have great appeal. The concept of "molecular mimicry" lays down that certain components of the wall of certain strains of steptococci fortuitously show close molecular similarity with connective tissue components of heart valves and myocardium and that antibodies produced against the bacterial antigen cross react against the heart, causing damage. The theory always had inconsistencies. The Aschoff body has no histological features that suggest humoral damage and bound gamma globulin is not present in the tissues. The present study shows that $T$ cells from the hearts of subjects who have had rheumatic fever can recognise both cardiac and bacterial wall antigens and the damage to the heart is probably cell based-a small but important change in thinking

M J DAVIES

\section{Human heart-infiltrating T-cell clones from rheumatic heart disease patients recognize both streptococcal and cardiac proteins}

\author{
L Guilherme, E Cunha-Neto, V Coelho, $R$ Snitcorvsky, P M A Pomerantzeff, $R$ V Assis, F Pedra, $\mathcal{F}$ Neumann, $A$ \\ Goldberg, M E Patarroyo, F Pileggi, 9 Kalil
}

Background- $\beta$-Hemolytic streptococcal infection in developing countries still causes thousands of cases of rheumatic heart disease, demanding surgical valve correction. Antigenic mimicry between self and streptococcal components has been proposed as the triggering factor leading to autoimmunity in individuals with genetic susceptibility. Although heart streptococcal-M protein cross-reactive antibodies have been demonstrated, heart tissue damage seems to be $T$ lymphocyte-dependent. We studied the infiltrating $T$ lymphocytes in rheumatic heart lesions with the aim of understanding the role of cellular immune response at the site of the lesions.

Methods and results-We obtained 107 T-cell clones from surgical fragments of cardiac tissue from four theumatic heart disease patients. We tested their capacity to recognize streptococcal $M$ protein-derived synthetic peptides and heart pro- teins. We found eight infiltrating T-cell clones from all four patients that simultaneously recognize streptococcal $M$ and heart proteins. Among the $M$ proteins sequences tested, only synthetic peptides corresponding to regions 1 through 25,81 through 103 , and 163 through 177 were simultaneously recognized with heart protein fractions. Interestingly, regions 81 through 103 and 163 through 177 have been known to bear heart cross-reactive epitopes at the antibody level. Five of these clones are $\mathrm{CD}^{+}$, and one is $\mathrm{CDB}^{+}$.

Conclusions-The presence of heart-M protein cross-reactive T-cell clones in rheumatic heart lesions suggests their direct involvement in the pathogenesis of this disease. The dissection of protective and pathogenic epitopes of streptococcal $M$ protein is an important step in allowing the development of a safe anti-streptococcal synthetic vaccine. (Circulation 1995;92:415-20.) 